\title{
Angiomyofibroblastoma Arising From The Pouch of Douglas: A Rare Case Report (16 Bold)
}

\author{
${ }^{*}$ Dr.Hemendra Kumar ${ }^{1}$,Dr. Anil Heroor ${ }^{2}$, Dr. Arul Vanan ${ }^{3}$,Dr. Pravin Pawar $^{4}$ \\ ${ }^{1}$ (colorectal surgery, fortis hospital, Mumbai; India) \\ 2(onco-surgery, fortis hospital, Mumbai; India) \\ 3 (general surgery, fortis hospital, Mumbai; India) \\ ${ }^{4}$ (senior resident surgery, fortis hospital, Mumbai; India) \\ *Corresponding author: *Dr.Hemendra Kumar
}

\begin{abstract}
Introduction: Angiomyofibroblastoma (AMF) is a rare soft-tissue tumor that most frequently affects the lower genital tracts of young to middle-aged women. These tumors commonly involve the vulva, perineum, vagina, uterine cervix but only rarely occur in the pelvis or retroperitoneum and rarely the inguinoscrotal regions of men. No case till date reported of AMF that originated from POD. To our knowledge, only FIVE cases of pelvic AMF have been reported at least so far.

Case Report: A 44 years old woman presented with intermittent dysuria \& UTI since 1 year. Her medical history was unremarkable. Her menstrual cycle was regular, painless, not have dysmenorrhoea or menorrhagia. A physical examination didn' $t$ ravel abnormalities. CT \& MRI suggest soft tissue tumor between uterus \& rectum. She was operated \& HPR leads diagnosis of AMF of POD.

Conclusion: $A M F$ of POD is extremely rare but is benign. a recognition of this entity is important to avoid misdiagnosis of other angiomyxoid neoplasms, leiomyoma. Preoperative diagnosis \& differentiation of AMF from other soft tissue tumor are challenging. The combination of radiological data, \& histological and IHC findings can confirm the diagnosis. It is important to identity this entity so that the patient can be saved from unnecessary follow up and intervention post excision.
\end{abstract}

Keywords: Angiomyofibroblastoma, Pouch of Douglas, Soft Tissue Tumor

\section{Introduction}

Angiomyofibroblastoma (AMF) is a rare soft-tissue tumor that most frequently affects the lower genital tracts of young to middle-aged women. Angiomyofibroblastoma was first described by Fletcher et al.(1). This tumor belongs to the group of genital mesenchymal tumors. These tumors commonly involve the vulva, perineum, vagina, uterine cervix $(2,3,4)$ but only rarely occur in the pelvis or retroperitoneum and rarely the inguinoscrotal regions of men (5). The tumors are well circumscribed rarely exceeding more than $12 \mathrm{~cm}$ in their greatest dimensions characterized histomorphologically by alternating zones of hypo and hypercellularity and randomly distributed thin walled vessels(6). No case till date reported of AMF that originated from POD.

\section{Case Report}

A 44 years old woman presented with intermittent dysuria \& UTI since 1 year. Her medical history was unremarkable. Her menstrual cycle was regular, painless and she did not have dysmenorrhoea or menorrhagia. A physical examination didn' $\mathrm{t}$ ravel abnormalities. Her ultrasonography (31/01/17) showed large well defined hyper reflected mass measuring $10.3 \times 8.3 \mathrm{~cm}$ in close relation to the vagina in POD with peripheral vasularity. CT scan (21/03/17) showed a11 X 8.7 X8.8 cm sized heterogeneously enhancing hypodense lesion in the pelvic predominantly in the POD contiguous to the anterior wall of rectum \& posterior wall of vagina and the cervix with loss of intervening fat planes. No enlarged lymph nodes were seen in pelvic cavity. MRI scan (21/03/17) showed a sized 9.3 X7.3 X8.6 cm sized heterogeneously enhancing soft tissue tumor with smooth encapsulated margins seen in POD in contiguity with the anterior wall of rectum as well as impinging on the cervix and vagina with moderate mass effect on the adjacent structures. The origin being indeterminate.

The patient was operated on 29/03/2017. Intraop finding shows a soft, regular shaped tumor between the rectum \& uterus. It had an intact capsule adhere to or invade the peripheral tissues. Then hysterectomy with complete local excision was carried out. Specimen sent for HPR. The excised tumor was well circumscribed and measured $11 \times 8.7 \times 8.8 \mathrm{~cm}$. The cut surface appeared tan in color and homogeneous with large flesh-like tissue composing of multiple well encapsulated tissues. No hemorrhage, necrosis or cystic changes were observed. Under a microscope, the tumor appeared well demarcated from the surrounding fat tissue was characterized by alternating hyper cellular and hypo cellular edematous zones containing thin walled blood vessels, suggestive of an AMF of POD. 
Immunohistochemistry (IHS) revealed that tumor cells were positive for desmin, estrogen receptor (50\%), progesterone receptor (50\%). The tumor was negative smooth muscle actin, S - 100 Protein, CD 34, CD 117 and B - Catenin. These features indicated a diagnosis of AMF. Post operative USG was normal. Now patient is on closed follow up and long term disease free survival is under assessment.

\section{Discussion}

AMF is a very rare recently described soft tissues neoplasm with vulva being the most common site of origin. Spermatic cord, urethra and vagina are the other rare sites of occurrence $(2,3,4]$ AMF was first described by Fletcher et al. in 1992(1). . In most reports, AMF has occurred in women aged between 20 and 50 years, i.e., during the reproductive years $(1,2)$. There are very rare reports of AMF occurring in male patients $(5,8)$. They are slowly growing painless masses that are well circumscribed. AMF is benign, soft-tissue tumor that shows myofibroblastic differentiation and represents neoplastic proliferation of stromal cells. Characteristic hypo and hypercellular areas are present with multiple randomly distributed blood vessels with the walls of the blood vessels being thin. $(8,9,10)$ A perivascular concentration of stromal cells is characteristically seen.

Its cause and pathogenesis are unknown at present. Since AMF is rare, no statistical data are available about its incidence in the general population. Most cases of AMF are benign, and only one case reported by Nielsen et al. reported of sarcomatous transformation in AMF (11). AMF is an important entity to be recognized, because it requires only simple excision and there are currently no publication reports of local recurrence or metastatic disease when excised complete. Although Weiss et al. mentioned a few cases with recurrence where the tumour was not completely excised (12). A rare lipomatous variant of AMF with local invasion has also been reported $(13,14)$. In most patients, AMF presents as a painless neoplasm located in the superficial regions of the lower female genital tract, such as the vulva and vagina (4), and are therefore easily detected. Tumors in the pelvis, iliac fossa or peritoneal cavity are extremely rare, and usually grow insidiously and reach a massive size before they are detected $(14,15,16,17)$. Their greatest dimensions have ranged from 3.8 to $25 \mathrm{~cm}$. To our knowledge, only five cases of pelvic AMF have been reported at least so far (Table 1). Table summarizes the major clinical and pathological features of previously reported cases. In a MEDLINE search terms "Angiomyofibroblastoma," and "Pouch of Douglas," we found no reports of Angiomyofibroblastoma that originating in the Pouch of Douglas.

Table 1 Clinical features of female pelvic AMF

\begin{tabular}{|c|c|c|c|c|}
\hline References & Age & Site & $\operatorname{Size}(\mathrm{cm})$ & Duration \\
\hline $\begin{array}{c}\text { Kobayashi, et al. } \\
\text { (14) }\end{array}$ & 28 & Pelvic cavity & $25 \times 14 \times 4$ & 2 years \\
\hline $\begin{array}{l}\text { Quintero, et al. } \\
\text { (15) }\end{array}$ & 28 & $\begin{array}{c}\text { Pelvic } \\
\text { retroperitoneum }\end{array}$ & $12 \times 9.6 \times 8$ & 1 year \\
\hline Lim, et al. (16) & 48 & $\begin{array}{l}\text { Posterior perivesical } \\
\text { space }\end{array}$ & $\begin{array}{c}3.8 \times 3.5 \times \\
2.8\end{array}$ & Not mentioned \\
\hline $\begin{array}{l}\text { Menendez, et } \\
\text { al.(17) } \\
\end{array}$ & 49 & Ischiorectal fossa & $5.5 \times 4.3 \times 2$ & 2 years \\
\hline Ping Qiu et al.(18) & 32 & Pelvic cavity & $\begin{array}{c}13.2 \times 5.8 \times \\
7.8\end{array}$ & 1 month \\
\hline
\end{tabular}

Several reports have analyzed the imaging features of AMFs. On perineal ultrasonography, AMFs appear as a soft-tissue mass with inhomogeneous mixed echogenicity, which corresponds to the cellular inhomogeneity found on histopathological examination. Therefore, the ultrasonographic characteristics of AMFs may help to differentiate them from other mesenchymal neoplasm. On CT imaging, AMFs most likely show moderate-to-strong enhancement, which may reflect the prominent vascularity of these tumors (19). IHC showed that the tumor expressed estrogen and progesterone receptors, which suggests that it might have originated as a neoplastic proliferation of hormonally responsive mesenchymal cells.

Our chief differential diagnoses were leiomyoma and aggressive angiomyxoma. Aggressive angiomyxoma is most likely to be confused with AMF because it shares many features with AMF including age at presentation, location, clinical manifestations and pathological entities. However, Aggressive angiomyxoma presents as a malignant, locally infiltrative, non-metastasizing stromal neoplasm with a strong tendency to recur. Since the morphology and IHC markers of AMF are similar to those of Aggressive angiomyxoma, differentiation between these two tumors is largely based on the appearance of the tumor margins (AMFs are well demarcated). The treatment of choice for AMF is simple total excision, which is usually curative, and there are almost no incidences of recurrences or metastasis after complete excision, which confirms the benign nature of AMF (20). AMF shows no propensity for infiltrative growth. 


\section{Conclusion}

AMF of POD is extremely rare but is benign. a recognition of this entity is important to avoid misdiagnosis of other angiomyxoid neoplasms \& leiomyoma. Preoperative diagnosis \& differentiation of AMF from other soft tissue tumor are challenging. The combination of radiological data, \& histological and IHC findings can confirm the diagnosis. It is important to identity this entity so that the patient can be saved from unnecessary follow up and intervention post excision.

\section{References}

[1]. Fletcher CD, Tsang WY, Fisher C, Lee KC, Chan JK: Angiomyofibroblastoma of the vulva. A benign neoplasm distinct from aggressive angiomyxoma. Am J Surg Pathol 1992, 16:373-382

[2]. Babala P, Biro C, Klacko M, Miklos P, Ondrus D: Angiomyofibroblastoma of the cervix uteri: a case report. Klin Onkol 2011, 24:133-136.

[3]. Mortele KJ, Lauwers GJ, Mergo PJ, Ros PR: Perineal angiomyofibroblastoma: CT and MR findings with pathologic correlation. J Comput Assist Tomogr 1999, 23:687-689.

[4]. Naheed S, Upadhyay K, Pradeep K: Angiomyofibroblastoma of the vulva. J Obstet Gynaecol 2011, 31:554-555.

[5]. Lee SH, Yang JW, Do JM, Seo DH, Jung JH, Chung KH, Lee JS, Hyun JS: Angiomyofibroblastoma-like tumor of the scrotum. Korean J Urol 2010, 51:365-367.

[6]. Mallya V, Sahai K, Rathi KR, Prasad U. Angiomyofibroblastoma: A diagnostic dilemma. J Can Res Ther 2015;11:655.

[7]. Saleh MM, Yassin AH, Zaklama MS: Recurrent angiomyofibroblastoma of the vagina: a case report. Eur J Gynaecol Oncol 2007 , 28:324.

[8]. McCluggage WG, White RG. Angiomyofibroblastoma of the vagina. J Clin Pathol 2000;53:803.

[9]. Fukunaga M, Nomura K, Matsumoto K, Doi K, Endo Y, Ushigome S. Vulval angiomyofibroblastoma. Clinicopathologic analysis of six cases. Am J Clin Pathol 1997;107:45- 51.

[10]. Hisaoka M, Kouho H, Aoki T, Daimaru Y, Hashimoto H. Angiomyofibroblastoma of the vulva: A clinicopathologic study of seven cases. Pathol Int 1995;45:487- 92.

[11]. Nielsen GP, Rosenberg AE, Young RH, Dickersin GR, Clement PB, Scully RE. Angiomyofibroblastoma of the vulva and vagina Mod Pathol 1996;9:284- 91.

[12]. Weiss SW, Gnepp DR, Bratthauer GL. Palisaded myofibroblastoma. A benign mesenchymal tumor of lymph node.Am J Surg Pathol1989;13:341-6.13

[13]. Laskin WB, Fetsch JF, Tavassoli FA: Angiomyofibroblastoma of the female genital tract: analysis of 17 cases including a lipomatous variant. Hum Pathol 1997, 28:1046-1055.

[14]. Kobayashi T, Suzuki K, Arai T, Sugimura H: Angiomyofibroblastoma arising from the fallopian tube. Obstet Gynecol 1999, 94:833834 .

[15]. Quintero C, Sasken H, Houck KL, Hernandez E: Angiomyofibroblastoma of the retroperitoneum: a case report. J Reprod Med 2007, 52:741-744.

[16]. Lim KJ, Moon JH, Yoon DY, Cha JH, Lee IJ, Min SJ: Angiomyofibroblastoma arising from the posterior perivesical space: a case report with MR findings. Korean J Radiol 2008, 9:382-385.

[17]. Menendez SP, Villarejo CP, Padilla VD, Munoz AV, Gonzalez LL, Martin FJ: Angiomyofibroblastoma of the right ischiorectal fosa. Cir Cir 2010, 78:448-450.

[18]. Qiu et al.: Giant pelvic angiomyofibroblastoma: case report and literature review. Diagnostic Pathology 2014 9:106.

[19]. Kim SW, Lee JH, Han JK, Jeon S: Angiomyofibroblastoma of the vulva: sonographic and computed tomographic findings with pathologic correlation. J Ultrasound Med 2009, 28:1417-1420.

[20]. Steeper TA, RosaiJ. Aggressive angiomyxoma of the female pelvis and perineum. Report of nine cases of a distinctive type of gynecologic soft-tissue neoplasm.Am J Surg Pathol1983;7: 463-75. 